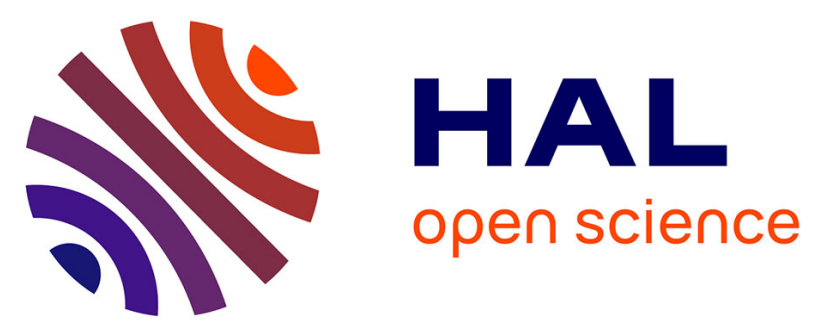

\title{
Imidazolium- and Pyrrolidinium-Based Ionic Liquids as Co-catalysts for CO2 Electroreduction in Model Molecular Electrocatalysis
}

Elli Vichou, Yun Li, Maria Gomez-Mingot, Marc Fontecave, Carlos M Sánchez-Sánchez

\section{To cite this version:}

Elli Vichou, Yun Li, Maria Gomez-Mingot, Marc Fontecave, Carlos M Sánchez-Sánchez. Imidazoliumand Pyrrolidinium-Based Ionic Liquids as Co-catalysts for $\mathrm{CO} 2$ Electroreduction in Model Molecular Electrocatalysis. Journal of Physical Chemistry C, 2020, 124 (43), pp.23764-23772. 10.1021/acs.jpcc.0c07556 . hal-03027294

\section{HAL Id: hal-03027294 \\ https://hal.sorbonne-universite.fr/hal-03027294}

Submitted on 27 Nov 2020

HAL is a multi-disciplinary open access archive for the deposit and dissemination of scientific research documents, whether they are published or not. The documents may come from teaching and research institutions in France or abroad, or from public or private research centers.
L'archive ouverte pluridisciplinaire HAL, est destinée au dépôt et à la diffusion de documents scientifiques de niveau recherche, publiés ou non, émanant des établissements d'enseignement et de recherche français ou étrangers, des laboratoires publics ou privés. 


\title{
Imidazolium and Pyrrolidinium Based Ionic Liquids as Co-catalysts for $\mathrm{CO}_{2}$ Electroreduction in Model Molecular Electrocatalysis
}

Elli Vichou ${ }^{\dagger, *}$, Yun Lit, Maria Gomez-Mingot ${ }^{\dagger, *}$, Marc Fontecave ${ }^{\dagger, *}$ and Carlos M. SánchezSánchez ${ }^{t, *}$

†Laboratoire de Chimie des Processus Biologiques, Collège de France, UMR 8229 CNRS, Sorbonne Université, PSL Research University, 11 Place Marcelin Berthelot, 75005 Paris, France

†Sorbonne Université, CNRS, Laboratoire Interfaces et Systèmes Electrochimiques, LISE, 75005 Paris, France

KEYWORDS: carbon dioxide reduction; ionic liquids; electrocatalysis; co-catalyst; molecular catalyst; electrostatic interaction

\begin{abstract}
The structure effect on the role of different ionic liquids (ILs) as simultaneous supporting electrolyte and co-catalyst for $\mathrm{CO}_{2}$ electroreduction in the presence of a model molecular catalyst $\left[\mathrm{Re}(\right.$ bpy $\left.)(\mathrm{CO})_{3} \mathrm{Cl}\right]$ has not been addressed yet. In particular, we varied the nature of the cation, anion and cation alkyl chain by a choice of 5 different ILs, including imidazolium and pyrrolidinium cations and we compared their results to benchmark supporting electrolyte. We report an overpotential diminution of $0.33 \mathrm{~V}$ for $\mathrm{CO}_{2}$ to $\mathrm{CO}$ conversion in the presence of ILs under $\mathrm{CO}_{2}$ catalytic conditions. We prove the IL cation-dependent overpotential diminution due to the electrostatic stabilization of the negatively-charged active form of the catalyst, being the $\pi-\pi$ stacking interaction provided by imidazolium cations responsible for their outstanding performance. Finally, a mechanistic explanation is provided to justify a weaker IL co-catalytic effect when $\mathrm{CO}_{2}$ electroreduction takes place in the presence of a proton source.
\end{abstract}




\section{INTRODUCTION}

Carbon dioxide $\left(\mathrm{CO}_{2}\right)$ electroreduction is an environmentally friendly approach that not only allows exploiting a waste material to produce valuable fuels or other chemicals, but also constitutes a promising solution for storing the intermittent energy originating from renewable sources. A first step in that direction is the electroreduction of $\mathrm{CO}_{2}$ to $\mathrm{CO}$, which can be used as feedstock in Fischer-Tropsch technologies that result in hydrocarbon products. However, the intrinsic inertness of the $\mathrm{CO}_{2}$ molecule is an obstacle to its direct reduction, which necessitates the use of a catalyst. Many metal complexes have been identified as efficient homogeneous catalysts for $\mathrm{CO}_{2}$ reduction, mainly contributing to ameliorating the rate, selectivity and efficiency of this reduction. ${ }^{1-4}$ Molecular electrocatalysts have been extensively studied since they offer a high degree of tunability through: i) the metal center, traditionally composed of a noble-metal $(\mathrm{Re}, \mathrm{Rh}, \mathrm{Ru}, \mathrm{Pd}, \ldots)^{5-8}$, although recently substituted by earth-abundant transition metals (Ni, Co, Mn, Fe,...) $)^{7-11}$ and ii) the choice of ligand, which tunes the electronic (thus the redox potential) and the geometric features ${ }^{12}$. A particularly selective molecular catalyst is the rhenium (I) complex [ $\left.\operatorname{Re}(\mathrm{bpy})(\mathrm{CO})_{3} \mathrm{Cl}\right]$, (where bpy is 2,2'-bipyridine), also known as Lehn's catalyst and here seen in Figure 1, hitherto referred to as complex [1], that has been demonstrated to selectively reduce $\mathrm{CO}_{2}$ to $\mathrm{CO}$ in an electrochemical and photochemical setup and detailed mechanistic studies have been developed ${ }^{5,6,13}$. Furthermore, studies have been carried out incorporating electron donating or electron withdrawing groups on the bpy ligand ${ }^{14-}$ ${ }^{16}$, as well as studies where this complex was attached to higher order systems or immobilized on surfaces ${ }^{17}$. Many of these studies aim at the increasing of the efficiency of this catalyst in terms of energy, that is to say maintaining high Faradaic yields for $\mathrm{CO}_{2}$ to $\mathrm{CO}$ conversion at the lowest possible overpotential, while not compromising on current density. Complex [1] thus provides a unique model for understanding basic aspects of molecular $\mathrm{CO}_{2}$ electroreduction catalysis. An alternative course of action in order to improve the electrocatalytic performance of molecular catalysts consists in altering the catalyst environment and more particularly the solvent and/or the supporting electrolyte. In an attempt to avoid favoring $\mathrm{H}_{2}$ formation over $\mathrm{CO}$ and the low $\mathrm{CO}_{2}$ solubility, $\mathrm{H}_{2} \mathrm{O}$ is often avoided as a solvent and the reaction is instead carried out in organic solvents. Another interesting approach is based on using ionic liquids (ILs) as solvent and supporting electrolyte simultaneously. ILs composition by an organic cation and an organic or inorganic anion assures the appropriate conductivity for $\mathrm{CO}_{2}$ conversion without any additional supporting electrolyte, as well as the wide necessary electrochemical potential window $^{18-21}$. Moreover, they are intrinsically non-flammable and redox-robust solvents, which mainly exhibit high solubility of $\mathrm{CO}_{2}$. This approach using complex [1] as catalyst has been already explored by Grills et al. ${ }^{22}$ showing an overpotential diminution of $0.45 \mathrm{~V}$ for $\mathrm{CO}_{2}$ to $\mathrm{CO}$ conversion by switching the solvent from acetonitrile to a pure IL, 1-Ethyl-3methylimidazolium tetracyanoborate ([EMIM][TCB]). Unfortunately, this was accompanied by a significant decrease in current due to diminution of the catalyst diffusion coefficient by two orders of magnitude 22 (from $1.4 \times 10^{-5} \mathrm{~cm}^{2} \mathrm{~s}^{-1}$ in acetonitrile to $3.0 \times 10^{-7} \mathrm{~cm}^{2} \mathrm{~s}^{-1}$ in IL). Indeed, the high viscosity of most ILs must not be overlooked, as it has an inversely proportional relationship to the conductivity of the solvent, it limits diffusion of soluble species and can lead to significant limitations in terms of maximum current density achieved ${ }^{23}$. An interesting alternative to overcome this limitation is the use of ILs as supporting electrolytes in binary mixtures with molecular solvents. Actually, the seminal work of Rosen et al. used a mixture with $18 \mathrm{~mol} \%$ of 1-Ethyl-3-methylimidazolium tetrafluoroborate ([EMIM][BF $]$ ) in water and achieved a relevant overpotential decrease for $\mathrm{CO}_{2}$ reduction on a silver electrode by forming adducts between $\mathrm{CO}_{2}$ and reduced imidazolium cations ${ }^{24}$. In fact, it has been demonstrated more recently ${ }^{25-27}$ that imidazolium cations are reduced on the electrode surface as a first step and then form adducts with $\mathrm{CO}_{2}$, which lowers the energy barrier of the unfavorable first one-electron reduction to $\mathrm{CO}_{2}{ }^{-}$. Using an Ag electrode as well, a key role has 
been assigned to the $\mathrm{C} 4$ and $\mathrm{C} 5$ protons of the imidazolium ring for hydrogen bond creation with $\mathrm{CO}_{2}{ }^{28}$. In addition to this, other ILs such as those based on pyrrolidinium and other nonreducible cations at the electrode surface have also demonstrated a co-catalyst role for the $\mathrm{CO}_{2}$ reduction by altering the electrochemical double layer ${ }^{26}$. Nevertheless, most of those studies using ILs have been carried out using heterogeneous electrocatalysts ${ }^{20,23,29,30}$. In contrast, much less work has been done exploring the role of ILs as supporting electrolyte in molecular electrocatalysis. So far, only a couple of studies have been devoted to study ILs co-catalytic contribution to $\mathrm{CO}_{2}$ reduction in organic solvents. Matsubara et al. ${ }^{31}$ combined linear sweep voltammetry and density functional theory (DFT) calculations to study the role of a unique imidazolium-based IL [EMIM] ${ }^{+}$in acetonitrile for $\mathrm{CO}_{2}$ electroreduction catalyzed by complex [1]. Additionally, Choi et al. ${ }^{32}$ reported the effect of another imidazolium-based IL (1-Butyl-3methylimidazolium tetrafluoroborate $\left.\left([\mathrm{BMIM}]\left[\mathrm{BF}_{4}\right]\right)\right)$ in dimethylformamide (DMF) as cocatalyst for $\mathrm{CO}_{2}$ reduction to $\mathrm{CO}$ using Iron tetraphenylporphyrin (FeTPP) as molecular electrocatalyst. In both cases, a significant positive shift of the catalytic onset potential was reported in the presence of ILs.

Taking all this into consideration, we aim at further studying the effects of different types of ILs in promoting $\mathrm{CO}_{2}$ electroreduction, however not as solvents but as supporting electrolytes, on model molecular catalysts, in particular addressing the questions of the role of the structure of the IL used and the type of interaction governing the enhanced catalysis observed in the presence of IL, which have not been addressed in detail yet.

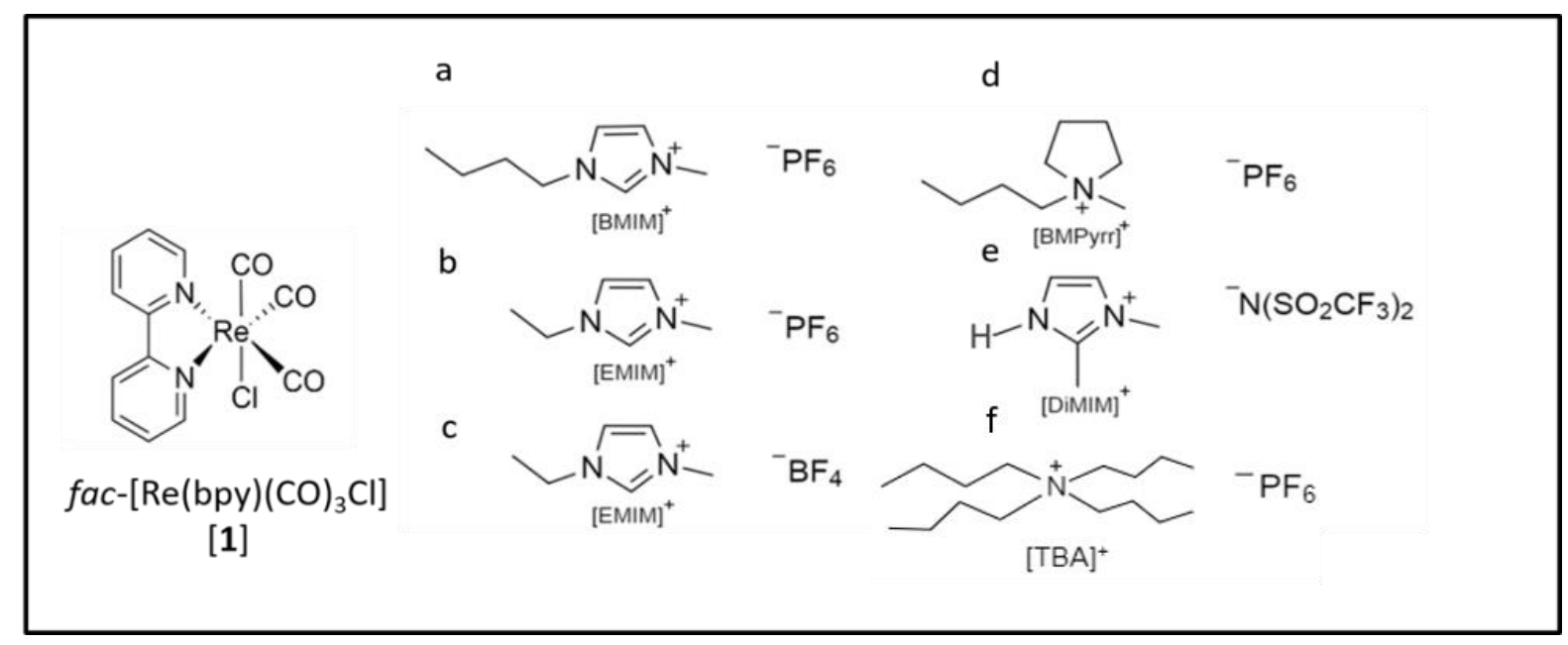

Figure 1. Structures of the $\left[\operatorname{Re}(\right.$ bpy $\left.)(\mathrm{CO})_{3} \mathrm{Cl}\right]$ complex [1], where bpy $=2,2$ '-bipyridine, and the supporting electrolytes: a) 1-Butyl-3-methylimidazolium hexafluorophosphate ([BMIM][PF 6$]$ ), b) 1-Ethyl-3-methylimidazolium hexafluorophosphate ([EMIM][PF6]), c) 1-Ethyl-3methylimidazolium tetrafluoroborate ([EMIM][BF $]$ ), d) 1-Butyl-1-methylpyrrolidinium hexafluorophosphate ([BMPyrr $\left.]\left[\mathrm{PF}_{6}\right]\right), \quad$ e) 1,2-Dimethylimidazolium bis(trifluoromethylsulfonyl)imide ([DiMIM] $\left[\mathrm{N}\left(\mathrm{SO}_{2} \mathrm{CF}_{3}\right)_{2}\right]$ ) and f) Tetrabutyl ammonium hexafluorophosphate $\left([\mathrm{TBA}]\left[\mathrm{PF}_{6}\right]\right)$.

For that purpose, we chose complex [1] as a model and five different ILs (protic and aprotic) as shown in Figure 1, allowing to compare four different cations and three different anions, as supporting electrolytes in acetonitrile. Three ILs from the imidazolium family, namely 1-Ethyl-

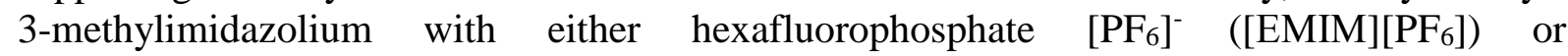
tetrafluoroborate $\left[\mathrm{BF}_{4}\right]^{-}\left([\mathrm{EMIM}]\left[\mathrm{BF}_{4}\right]\right)$ as the counter-anion, 1-Butyl-3-methylimidazolium 
hexafluorophosphate

([BMIM] $\left.\left[\mathrm{PF}_{6}\right]\right)$,

1,2-Dimethylimidazolium

bis(trifluoromethylsulfonyl)imide ([DiMIM] $\left.\left[\mathrm{N}\left(\mathrm{SO}_{2} \mathrm{CF}_{3}\right)_{2}\right]\right)$, a protic IL containing an acidic proton, and one IL from the pyrrolidinium family, namely 1-Butyl-1-methylpyrrolidinium hexafluorophosphate ([BMPyrr] $\left.\left[\mathrm{PF}_{6}\right]\right)$.

\section{EXPERIMENTAL SECTION}

Reactants: Anhydrous acetonitrile of $99.99 \%$ purity $\left(\mathrm{CH}_{3} \mathrm{CN}\right)$, which is used as the solvent, tetrabutyl ammonium hexafluorophosphate $\left([\mathrm{TBA}]\left[\mathrm{PF}_{6}\right],>99 \%\right)$, which is used as a supporting electrolyte and 2,2,2-trifluoroethanol, (TFE, > $99 \%$ ), which is used as a proton source, are all purchased from Sigma-Aldrich. Complex [1] was commercially available (Strem Chemicals, > $99 \%$ ) and all Ionic Liquids used as supporting electrolytes: 1-Butyl-3methylimidazolium hexafluorophosphate ([BMIM] $\left.\left[\mathrm{PF}_{6}\right]\right)(99 \%, 267 \mathrm{cP})$, 1-Ethyl-3methylimidazolium hexafluorophosphate ([EMIM] $\left.\left[\mathrm{PF}_{6}\right]\right)\left(99 \%\right.$, Melting point: $\left.64{ }^{\circ} \mathrm{C}\right), 1-$ Ethyl-3-methylimidazolium tetrafluoroborate ([EMIM][BF 4$)(>98 \%, 33.8 \mathrm{cP}), 1-B u t y l-1-$ methylpyrrolidinium hexafluorophosphate ([BMPyrr] $\left.\left[\mathrm{PF}_{6}\right]\right)\left(99 \%\right.$, Melting point: $\left.87^{\circ} \mathrm{C}\right), 1,2-$ Dimethylimidazolium bis(trifluoromethylsulfonyl)imide ([DiMIM] $\left.\left[\mathrm{N}\left(\mathrm{SO}_{2} \mathrm{CF}_{3}\right)_{2}\right]\right)(98 \%, 106$ $\mathrm{cP})$ were purchased from Io-li-tec (Germany).

ILs drying treatment and water quantification: Before use, all ILs were vacuum-dried overnight under stirring using a vacuum pump and then, stored in a glove box under Argon. The drying procedure followed was reported by M.A. Montiel et al. ${ }^{33}$ All solutions of ILs in acetonitrile (ILs/ $\mathrm{CH}_{3} \mathrm{CN}$ ) were freshly prepared in the glove box before each experiment. Water content in all acetonitrile solutions was quantified by Karl Fischer titration (Model 756/831 KF MettlerToledo), which consist in an electrochemical coulometric method that consumes water in the oxidation reaction and allows quantifying even traces of humidity in samples. The titration samples mass was of $(0.3-0.5) \mathrm{g}$ and the measurement range was of $20-3000 \mathrm{ppm}$ (detection limit for $\mathrm{H}_{2} \mathrm{O}$ quantification $2 \mathrm{ppm}$ ). The final concentration of water present in each IL/ $\mathrm{CH}_{3} \mathrm{CN}$ solution was: $88 \mathrm{ppm}$ for $0.5 \mathrm{M}$ [BMIM] $\left[\mathrm{PF}_{6}\right], 250 \mathrm{ppm}$ for $0.5 \mathrm{M}$ [EMIM][PF 6$], 151 \mathrm{ppm}$ for

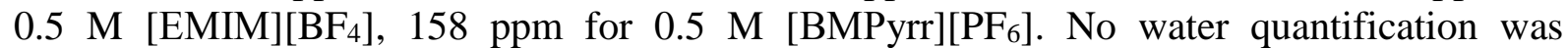
performed for [DiMIM] $\left[\mathrm{N}\left(\mathrm{SO}_{2} \mathrm{CF}_{3}\right)_{2}\right]$. Pure acetonitrile water content was $77 \mathrm{ppm}$. Values are shown in Table $\mathrm{S} 1$.

Electrochemical Studies: All electrochemical experiments were performed on a VSP-300 potentiostat (Bio-Logic Science Instruments SAS) and were conducted at room temperature (20 $\pm 2{ }^{\circ} \mathrm{C}$ ) in $\mathrm{CH}_{3} \mathrm{CN}$. Either [TBA] $\left[\mathrm{PF}_{6}\right]$ or one of the ILs studied was used as supporting electrolyte in solution. $\mathrm{Ar}(>99.99 \%)$ and $\mathrm{CO}_{2}(>99.99 \%)$ gases used to saturate solutions were purchased from Air Liquide and passed through a gas filter (model CP17973, Agilent) before entering in the electrochemical cell ${ }^{33}$. This filter removes traces of oxygen, moisture and hydrocarbons and results in a concentration of $\mathrm{H}_{2} \mathrm{O}$ of the gas outlet lower than $0.1 \mathrm{ppm}$. The cyclic voltammetry (CV) experiments were carried out in a three electrode setup, with a $3 \mathrm{~mm}$ diameter glassy carbon (GC) electrode as a working electrode, which was polished on a polishing cloth on a $1 \mu \mathrm{m}$ diamond suspension (Struers), sonicated for 10 seconds, thoroughly rinsed with ethanol and dried under a stream of nitrogen prior to experiments. A platinum wire was used as a counter electrode and was previously flame annealed. The reference electrode was a silver chloride coated silver wire and all potentials were calibrated using the Ferrocenium/Ferrocene $\left(\mathrm{Fc}^{+} / \mathrm{Fc}\right)$ redox couple as internal standard, which was added in solution at the end of each measurement. Only the third cycle of all CVs is shown, although no difference in consecutive scans has been observed. Catalytic potential $\left(\mathrm{E}_{\mathrm{cat} / 2}\right)$ corresponds to the value at half of the catalytic current. The overpotential $(\eta)$ was calculated from the difference between

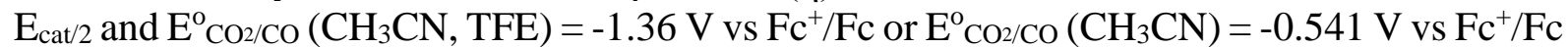


in the presence and in the absence of a proton source in solution, respectively ${ }^{14,34}$. Catalytic response was determined from $\mathrm{CV}$ by calculating the ratio between reduction peak current under either $\mathrm{CO}_{2}$ or $\left(\mathrm{CO}_{2}+\mathrm{TFE}\right)$ and reduction peak current under inert conditions $\left(\mathrm{i}_{\text {cat }} / \mathrm{i}_{\mathrm{p}}\right)$. Values are shown in Tables 1 and 2.

Controlled potential electrolysis (CPE) experiments were conducted in a gas-tight twocompartment electrochemical cell with a glass frit separating the anodic and cathodic compartments. The working electrode was a $1 \mathrm{~cm}^{2}$ glassy carbon plate, the counter electrode was a platinum mesh and the reference electrode was a silver chloride coated silver wire, which was calibrated with Ferrocene as an internal redox reference. Anolyte and catholyte contained acetonitrile and $0.5 \mathrm{M}$ of supporting electrolyte (either individual ILs or [TBA] $\left[\mathrm{PF}_{6}\right]$ ), but only in the catholyte $1 \mathrm{mM}$ of complex $\left[\mathrm{Re}(\mathrm{bpy})(\mathrm{CO})_{3} \mathrm{Cl}\right]$ was added. Ohmic losses in the cell were minimized by placing the electrodes as close as possible to each other and stirring both solution compartments during the experiment. Moreover, $85 \%$ of the electrolyte resistance was compensated by the ohmic drop compensation module of the potentiostat. Both solution compartments were saturated with $\mathrm{CO}_{2}$ during at least 20 minutes before starting the electrolysis, but no more gas was bubbled during the electrolysis. Gas products were quantified by gas chromatography (Model 8610C SRI Instruments) from $50 \mu \mathrm{L}$ aliquots of the headspace of both compartments. Hydrogen $\left(\mathrm{H}_{2}\right)$ and carbon monoxide $(\mathrm{CO})$ were detected by a thermal conductivity detector (TCD) and a flame ionization detector (FID), respectively. Liquid products were evaluated using an ionic exchange chromatograph (Metrohm 883 Basic IC) equipped with a Metrosep A Supp 5 column and a conductivity detector. However, no significant amounts of liquid products were detected. Faradaic Yield (FY) is the ratio between the charge consumed to form each reaction product and the total circulated charge. FY is corrected to account for the initial 2 electron reduction of the molecular catalyst $(1 \mathrm{mM}$ in solution) necessary to generate its active form. Catalyst activation charge $=$ [number of electrons $*$ Faraday constant $*$ mol of catalyst $]=\left[2 * 96485 * 6.06 * 10^{-6}\right]=1.17 \mathrm{C}$. In order to compare all CPE results, a constant total number of coulombs $(14 \mathrm{C})$ has been used in all electrolyses, but different time was necessary to reach those $14 \mathrm{C}$ depending on the current density achieved in each particular electrolysis. Four repetitions of each CPE experiment were used to obtain the average FY and the standard deviation reported in Table 3.

\section{RESULTS}

In Figure 2 are shown the cyclic voltammograms $(\mathrm{CVs})$ of an acetonitrile solution containing 1 $\mathrm{mM}$ complex [1] under inert conditions (Ar saturated) in the presence of different supporting electrolytes including conventional benchmark $\left[\mathrm{TBA}^{-}\left[\mathrm{PF}_{6}\right]\right.$, one pyrrolidinium based IL $[\mathrm{BMPyrr}]\left[\mathrm{PF}_{6}\right]$ and 3 different imidazolium based ILs ([BMIM][PF 6 , [EMIM] $\left.\mathrm{PF}_{6}\right]$ and $\left.[\mathrm{EMIM}]\left[\mathrm{BF}_{4}\right]\right)$. All supporting electrolyte structures are shown in Figure 1. A constant electrolyte concentration of $0.5 \mathrm{M}$ was used throughout the study to rule out any effect from increasing ionic strength. Moreover, this concentration proved a good compromise by providing a relevant overpotential diminution and enough conductivity when ILs were in solution (see Figure S1). Furthermore, all ILs were dried before use, since $\mathrm{H}_{2} \mathrm{O}$ content in ILs have been demonstrated to play a relevant role ${ }^{35,36}$. According to previous reports ${ }^{5,14,37}$, the first reduction wave shown in Figure 2 has been attributed to a one-electron reversible reduction centered on the bpy ligand (bpy to bpy ${ }^{-}$) and the second more cathodic wave to a one-electron irreversible or quasi-reversible metal centered reduction $\left(\operatorname{Re}^{\mathrm{I}}\right.$ to $\left.\mathrm{Re}^{0}\right)$. Figure 2 a compares the behavior of complex [1] in the presence of $[\mathrm{TBA}]\left[\mathrm{PF}_{6}\right]$ and 2 different IL cations (pyrrolidinium and imidazolium), which keep constant the alkyl chain length in the cation. The anion $\left[\mathrm{PF}_{6}\right]^{-}$is kept unchanged in all 3 cases to evaluate only the role of the cation. We observed that: (i) both redox processes were significantly shifted anodically in the presence of both ILs as compared to 
[TBA] $\left[\mathrm{PF}_{6}\right]$; (ii) the potential shift of the second reduction wave was much larger than that of the first reduction wave; (iii) these shifts greatly depended on the nature of the IL cation, being much more relevant when the imidazolium cation was present in solution, with the trend in potentials being $\mathrm{IM}^{+}>\mathrm{Pyrr}^{+}>\mathrm{TBA}^{+}$. Figure $2 \mathrm{~b}$ compares the complex [1] performance in the presence of 3 different imidazolium based ILs by studying the effect of the alkyl chain length in the cation and the nature of the anion. It shows that those two parameters have only a minor effect on the CVs of complex [1]. Table 1 reports the characteristic potentials for all reduction peaks shown in Figure 2. Thus, the first reduction potential is shifted positively between 60 and $210 \mathrm{mV}$ by replacing $[\mathrm{TBA}]\left[\mathrm{PF}_{6}\right]$ with an IL, meanwhile the second reduction peak is shifted also positively between 190 and $370 \mathrm{mV}$ depending on the IL used, with [EMIM] [BF 4 being the one displaying the most important potential shift in Figure $2 \mathrm{~b}$. We equally observed that the current density displayed in Figure 2 remains very similar in the presence and absence of ILs and do not vary according to the nature of the IL. These observations strongly suggest an interaction between the reduced form of the complex and the IL cation, which nicely results in more positive redox potentials for the reduction of complex [1]. Figure $\mathrm{S} 2$ shows that complex [1] in the presence of [DiMIM] $\left[\mathrm{N}\left(\mathrm{SO}_{2} \mathrm{CF}_{3}\right)_{2}\right]$, the only protic IL tested in this work, whose structure is also shown in Figure 1e, does not show its two characteristic reduction waves in the mixture IL/ $\mathrm{CH}_{3} \mathrm{CN}$. Figure $\mathrm{S} 2$ seems to indicate the direct proton reduction present in $[\mathrm{DiMIM}]^{+}$at the GC electrode surface.

The reason why we dried the ILs before use resided in the observation that the $\mathrm{H}_{2} \mathrm{O}$ content in the IL/CH${ }_{3} \mathrm{CN}$ solutions was significant and had a relevant impact on the potentials displayed by the two reduction waves of complex [1]. Table $\mathrm{S} 1$ shows the $\mathrm{H}_{2} \mathrm{O}$ concentration in the IL/ $\mathrm{CH}_{3} \mathrm{CN}$ solutions quantified by Karl Fischer titration using dried and not dried ILs. In some cases, $\mathrm{H}_{2} \mathrm{O}$ concentration greatly decreased after drying by an order of magnitude. In Figure $\mathrm{S} 3$, CVs of complex [1] in $\mathrm{CH}_{3} \mathrm{CN}$ solutions using dried ILs and not dried ILs are compared and in all 4 cases the reduction waves of complex [1] were cathodically shifted and the current densities were larger when not dried ILs were used as supporting electrolyte, proving that the drying process of ILs proposed here, in coordination with adopting specific filters that blocked humidity in the gas inlet were important in order to reach reliable results. Furthermore, it indicated that not only the interactions between the complex and the IL that facilitate the reduction were partly suppressed in the presence of $\mathrm{H}_{2} \mathrm{O}$, but also under these conditions some proton reduction catalysis may occur. All experiments below, and as those reported in Figure 2 , have thus been carried out with dried ILs exclusively.

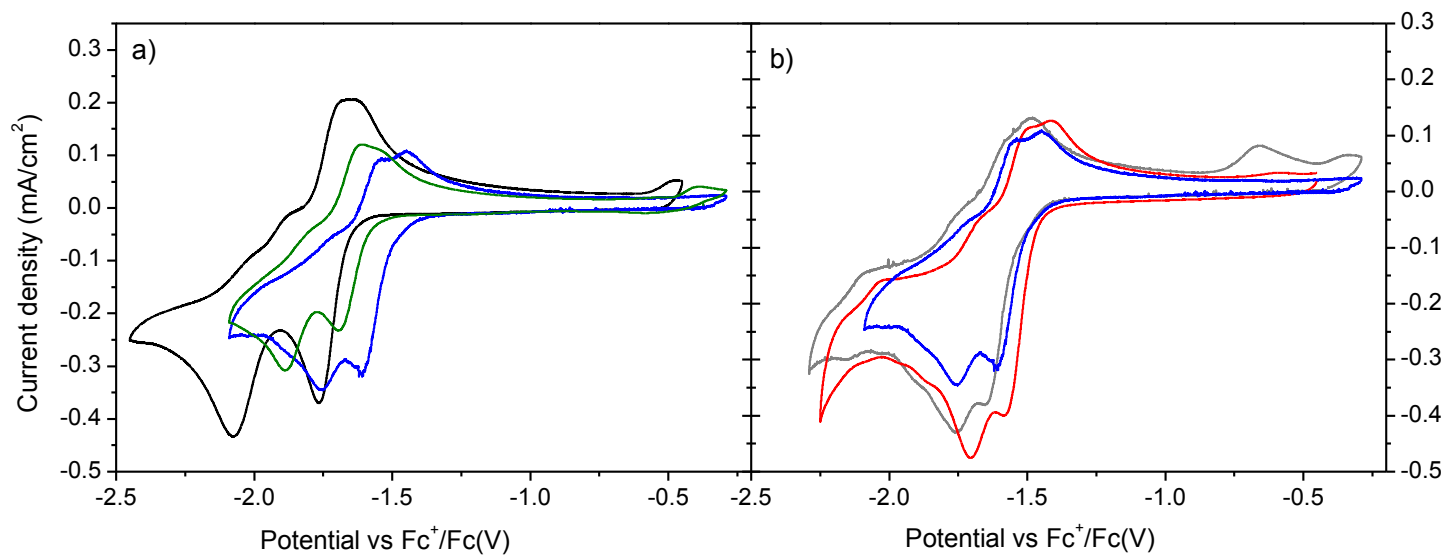

Figure 2. Cyclic Voltammograms of $1 \mathrm{mM}$ complex [1] and $0.5 \mathrm{M}$ of different supporting electrolytes in acetonitrile solution under Ar. (a) $[\mathrm{TBA}]\left[\mathrm{PF}_{6}\right]$ (black plot), $[\mathrm{BMPyrr}]\left[\mathrm{PF}_{6}\right]$ 
(green plot) and [BMIM] $\left[\mathrm{PF}_{6}\right]$ (blue plot) and (b) [EMIM] $\left[\mathrm{BF}_{4}\right]$ (red plot), [EMIM] $\left[\mathrm{PF}_{6}\right]$ (grey plot) and [BMIM] $\left[\mathrm{PF}_{6}\right]$ (blue plot). Scan rate $0.1 \mathrm{~V} \mathrm{~s}^{-1}$. Room temperature: $20 \pm 2{ }^{\circ} \mathrm{C}$.

We subsequently studied the catalytic properties of complex [1] for $\mathrm{CO}_{2}$ electroreduction in the presence of all different ILs investigated. Thus, Figure 3 shows CVs of complex [1] under catalytic $\mathrm{CO}_{2}$ conditions without an added proton source. A catalytic wave for $\mathrm{CO}_{2}$ electroreduction, as expected, was observed at the second complex reduction process, where the catalytically active 2-electron reduced species is generated. Thus, a significant increase in current ( $\mathrm{i}_{\text {cat }}$ ) was observed at the second potential peak in all $\mathrm{CVs}$ of Figure 3 when $\mathrm{CO}_{2}$ was present in solution. Figure 3a compares the catalyst behavior in the presence of conventional benchmark [TBA] $\left[\mathrm{PF}_{6}\right]$ electrolyte and 2 different IL cations (pyrrolidinium and imidazolium), which keep constant the alkyl chain length in the cation. The anion $\left[\mathrm{PF}_{6}\right]^{-}$is kept unchanged in all 3 cases. A relevant positive shift due to the presence of ILs in solution is displayed for both reduction waves following the same trend already observed in Figure 2 a under inert conditions $\left(\mathrm{IM}^{+}>\mathrm{Pyrr}^{+}>\mathrm{TBA}^{+}\right)$. Figure $3 \mathrm{~b}$ compares the catalyst behavior in the presence of 3 different imidazolium based ILs by studying the effect of the alkyl chain length in the cation and the nature of the anion. Both ILs containing $[\mathrm{EMIM}]^{+}$cation showed the largest $\mathrm{i}_{\text {cat }}$ value. Table 1 reports an estimation of catalytic currents obtained in each case by comparison with the corresponding current obtained under inert conditions (using the ratio $i_{\text {cat }} / i_{p}$ ) and the characteristic potentials for the catalytic peaks shown in Figure 3 . Thus, the largest $i_{\text {cat }} / i_{p}$ ratios were obtained in $0.5 \mathrm{M}$ [EMIM] $\left[\mathrm{PF}_{6}\right]$ and $0.5 \mathrm{M}[\mathrm{EMIM}]\left[\mathrm{BF}_{4}\right]$ in $\mathrm{CH}_{3} \mathrm{CN}$. Furthermore, Table 1 reports $\mathrm{E}_{\mathrm{cat} / 2}$ values, potentials corresponding to half of the catalytic peak current, as proposed by Kubiak's group, ${ }^{14}$ showing that catalysis occurs at more positive potentials in the presence of ILs, with positive shifts from 200 to $330 \mathrm{mV}$ depending on the IL used, with [EMIM][BF 4 ] being the one displaying the most important potential shift and therefore, the lowest overpotential $(1.19 \mathrm{~V})$. Nevertheless, all 3 imidazolium based ILs exhibited very close overpotential values. Finally, Figure $\mathrm{S} 4$ shows that in the case of using [DiMIM] $\left[\mathrm{N}\left(\mathrm{SO}_{2} \mathrm{CF}_{3}\right)_{2}\right]$ in solution, the same reduction current is observed when the $\mathrm{CV}$ was recorded in the absence or in the presence of $\mathrm{CO}_{2}$, reflecting that reduction of protons provided by the IL is the predominant reaction. 


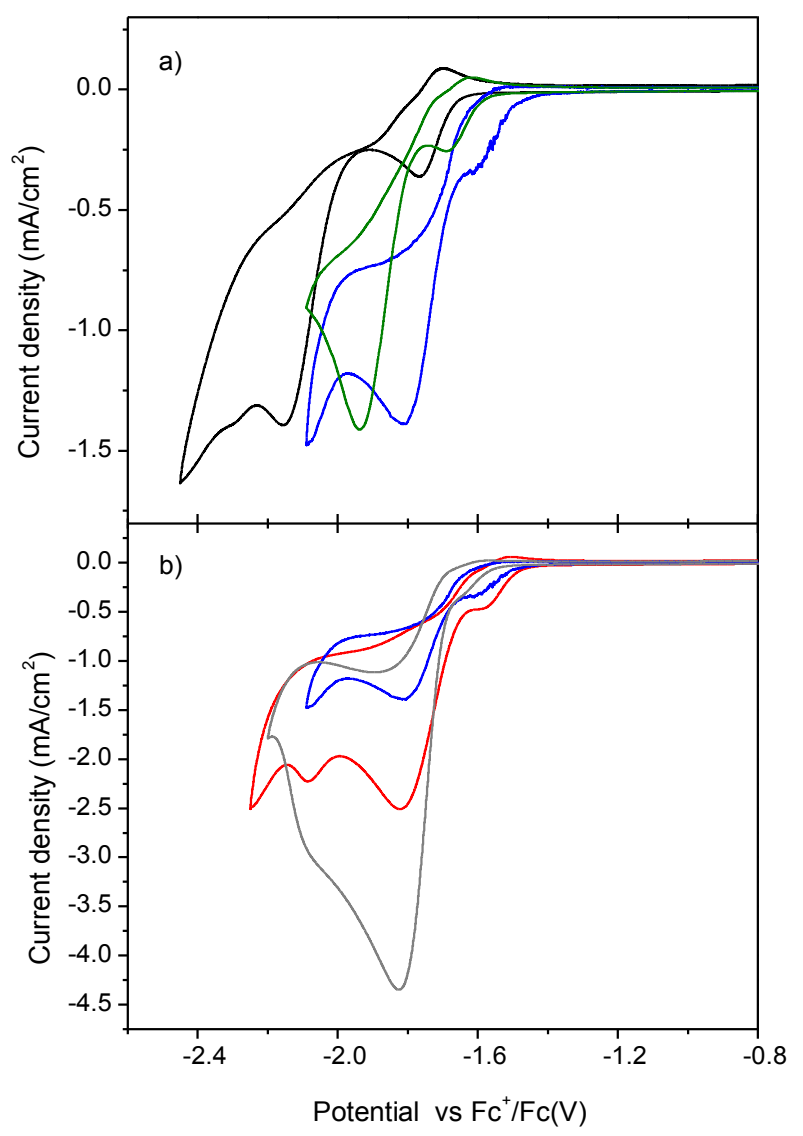

Figure 3. Cyclic Voltammograms of $1 \mathrm{mM}$ complex [1] and $0.5 \mathrm{M}$ of different supporting electrolytes in $\mathrm{CO}_{2}$-saturated acetonitrile solution. (a) [TBA] $\left[\mathrm{PF}_{6}\right]$ (black plot), [BMPyrr] $\left[\mathrm{PF}_{6}\right]$ (green plot) and [BMIM] $\left[\mathrm{PF}_{6}\right]$ (blue plot) and (b) $[\mathrm{EMIM}]\left[\mathrm{PF}_{6}\right]$ (grey plot), [EMIM] $\left[\mathrm{BF}_{4}\right]$ (red plot) and $[\mathrm{BMIM}]\left[\mathrm{PF}_{6}\right]$ (blue plot). Scan rate $0.1 \mathrm{~V} \mathrm{~s}^{-1}$. Room temperature: $20 \pm 2{ }^{\circ} \mathrm{C}$.

\begin{tabular}{llllll}
\hline & \multicolumn{2}{l}{$\begin{array}{l}\text { Under inert } \\
\text { conditions }\end{array}$} & \multicolumn{3}{l}{$\begin{array}{l}\text { Under catalytic CO} \mathbf{C O}_{2} \\
\text { conditions }\end{array}$} \\
\cline { 2 - 6 } & $\mathrm{E}_{\mathrm{p} 1 / 2}(\mathrm{~V})^{\mathrm{a}}$ & $\mathrm{E}_{\mathrm{p}}(\mathrm{V})^{\mathrm{a}}$ & $\mathrm{E}_{\mathrm{cat} / 2}(\mathrm{~V})^{\mathrm{a}}$ & $\eta(\mathrm{V})^{\mathrm{b}}$ & $\mathrm{i}_{\mathrm{cat}} / \mathrm{i}_{\mathrm{p}}$ \\
{$[\mathrm{TBA}]\left[\mathbf{P F}_{6}\right]$} & -1.70 & -2.07 & -2.06 & 1.52 & 3.2 \\
{$[\mathbf{B M I M}]\left[\mathbf{P F}_{6}\right]$} & -1.52 & -1.76 & -1.75 & 1.21 & 4.0 \\
{$[\mathbf{B M P y r}]\left[\mathbf{P F}_{6}\right]$} & -1.64 & -1.88 & -1.86 & 1.32 & 4.6 \\
{$[\mathbf{E M I M}]\left[\mathbf{P F}_{6}\right]$} & -1.57 & -1.75 & -1.74 & 1.20 & 9.9 \\
{$[\mathbf{E M I M}]\left[\mathbf{B F}_{4}\right]$} & -1.49 & -1.70 & -1.73 & 1.19 & 5.3 \\
\hline
\end{tabular}

Table 1. Descriptors for $1 \mathrm{mM}$ complex [1] under inert conditions (Ar) and $\mathrm{CO}_{2}$ catalytic conditions in $0.5 \mathrm{M}$ of each supporting electrolyte in $\mathrm{CH}_{3} \mathrm{CN}$. Potential of the $1^{\text {st }}$ reduction peak $\left(E_{p 1 / 2}\right)$, potential of the $2^{\text {nd }}$ reduction peak $\left(E_{p}\right)$, catalytic reduction potential $\left(E_{c a t / 2}\right)$, overpotential $(\eta)$, and ratio of the catalytic peak current and the peak current under inert conditions $\left(\mathrm{i}_{\mathrm{cat}} / \mathrm{i}_{\mathrm{p}}\right)$. ${ }^{\text {aP }}$ Potentials are referred vs. $\mathrm{Fc}^{+} / \mathrm{Fc}(\mathrm{V}),{ }^{b}$ Determined based on $\mathrm{E}_{\mathrm{cat} / 2}$ using $\mathrm{E}^{0} \mathrm{CO}_{2} / \mathrm{CO}\left(\mathrm{CH}_{3} \mathrm{CN}\right)=-0.541 \mathrm{~V}$ vs $\mathrm{Fc}^{+} / \mathrm{Fc}$. 
It has been demonstrated that $\mathrm{CO}_{2}$ electroreduction catalyzed by molecular complexes requires the presence of a proton source in solution to facilitate the proton-coupled electron transfers that are associated with $\mathrm{CO}_{2}$ reduction. Following previous studies, ${ }^{14}$ the weak Brønsted acid TFE was identified as an appropriate proton source and 1.5 M an optimal TFE concentration to give an enhanced activity for $\mathrm{CO}_{2}$ electroreduction, which was also the case when ILs were in solution (Figure S5). Thus, Figure 4 shows $\mathrm{CVs}$ of complex [1] under catalytic $\mathrm{CO}_{2}$ conditions in the presence of $1.5 \mathrm{M} \mathrm{TFE}$ as a proton source and $0.5 \mathrm{M}$ of all different supporting electrolytes studied here. Table 2 reports an estimation of catalytic currents obtained in each case by comparison versus inert conditions $\left(i_{c a t} / i_{p}\right)$ and the characteristic potentials for the catalytic reduction peaks shown in Figure 4. As expected from the literature, ${ }^{14}$ when using [TBA] $\left[\mathrm{PF}_{6}\right]$ as supporting electrolyte, a significant shift $(130 \mathrm{mV})$ towards more positive potentials is observed in the catalytic $\mathrm{CO}_{2}$ reduction wave due to the addition of a weak acid such as TFE. In contrast, in the case of pyrrolidinium based $\mathrm{IL}$, the $\mathrm{E}_{\text {cat } / 2}$ in $\mathrm{CO}_{2}$-saturated

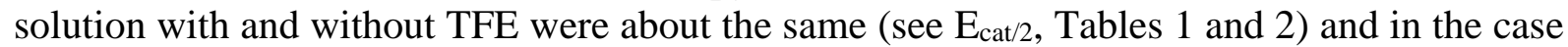
of all 3 imidazolium based ILs, we observed a significant shift $(\sim 150 \mathrm{mV})$ towards more negative potentials when TFE was present in solution. Nevertheless, catalysis still occurred at potentials slightly more positive in the presence of ILs as compared to benchmark supporting electrolyte $[\mathrm{TBA}]\left[\mathrm{PF}_{6}\right]$ by $30-70 \mathrm{mV}$, being $[\mathrm{BMIM}]\left[\mathrm{PF}_{6}\right]$ and $[\mathrm{BMPyrr}]\left[\mathrm{PF}_{6}\right]$ the ones displaying the most positive $\mathrm{E}_{\mathrm{cat} / 2}$ and the lowest overpotential $(0.50 \mathrm{~V}$ and $0.52 \mathrm{~V}$, respectively). Another effect of the ILs in solution appeared to be a moderate enhancement of maximum current density as compared to $\left[\mathrm{TBA}^{\mathrm{B}}\right]\left[\mathrm{PF}_{6}\right]$, with $[\mathrm{EMIM}]\left[\mathrm{BF}_{4}\right]$ giving the highest value, in the vicinity of $10 \mathrm{~mA} / \mathrm{cm}^{2}$. However, $[\mathrm{BMPyrr}]\left[\mathrm{PF}_{6}\right]$ exhibits the highest catalytic current ratio due to its lower current under inert conditions.

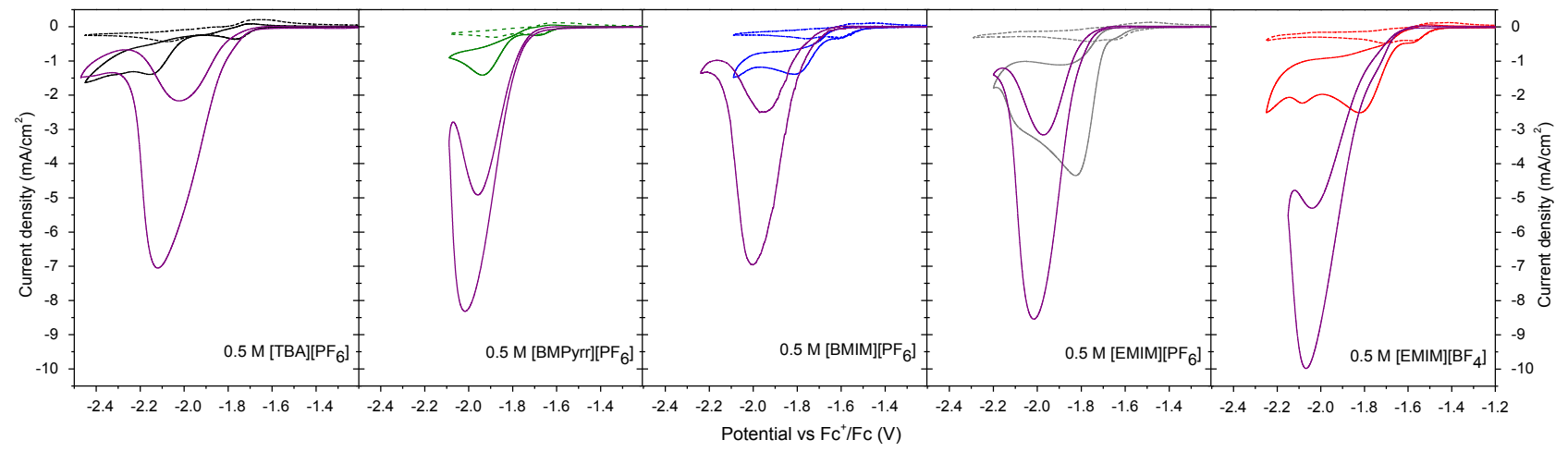

Figure 4. Cyclic Voltammograms of $1 \mathrm{mM}$ complex [1] and $0.5 \mathrm{M}$ of different supporting electrolytes in acetonitrile solution under $\mathrm{Ar}$ (dashed plots) and $\mathrm{CO}_{2}$ (solid plots) colored as follows: [TBA] $\left[\mathrm{PF}_{6}\right]$ (black), $[\mathrm{BMPyrr}]\left[\mathrm{PF}_{6}\right]$ (green), [BMIM][PF 6 (blue), [EMIM] $\left[\mathrm{PF}_{6}\right]$ (grey), and [EMIM] $\left[\mathrm{BF}_{4}\right]$ (red), and $\mathrm{CO}_{2}$ with $1.5 \mathrm{M}$ TFE (solid purple plots in all cases). Scan rate $0.1 \mathrm{~V} \mathrm{~s}^{-1}$. Room temperature: $20 \pm 2{ }^{\circ} \mathrm{C}$. 


\begin{tabular}{|c|c|c|c|}
\hline & $E_{\text {cat } / 2}(V)^{a}$ & $\eta(V)^{b}$ & $\mathbf{i}_{\text {cat }} / \mathbf{i p}_{\mathbf{p}}$ \\
\hline$[\mathrm{TBA}]\left[\mathrm{PF}_{6}\right]$ & -1.93 & 0.57 & 16.0 \\
\hline$[\mathrm{BMIM}]\left[\mathrm{PF}_{6}\right]$ & -1.86 & 0.50 & 20.2 \\
\hline$[\mathrm{BMPyrr}]\left[\mathrm{PF}_{6}\right]$ & -1.88 & 0.52 & 27.0 \\
\hline$[\mathrm{EMIM}]\left[\mathrm{PF}_{6}\right]$ & -1.90 & 0.54 & 19.5 \\
\hline$[\mathrm{EMIM}]\left[\mathrm{BF}_{4}\right]$ & -1.90 & 0.54 & 20.9 \\
\hline
\end{tabular}

Table 2. Comparison of the catalytic parameters of $1 \mathrm{mM}$ complex [1] under a $\mathrm{CO}_{2}$ atmosphere in the presence of $1.5 \mathrm{M}$ of TFE in $0.5 \mathrm{M}$ of each supporting electrolyte in $\mathrm{CH}_{3} \mathrm{CN}$ : catalytic potential $\left(E_{\text {cat } / 2}\right)$, overpotential $(\eta)$, and ratio of the catalytic peak current and the peak current under inert conditions $\left(\mathrm{i}_{\mathrm{cat}} / \mathrm{i}_{\mathrm{p}}\right)$. ${ }^{\mathrm{a}}$ Potentials are referred vs. $\mathrm{Fc}^{+} / \mathrm{Fc}(\mathrm{V}),{ }^{\mathrm{b}}$ Determined based on $\mathrm{E}_{\text {cat } / 2}$ using $\mathrm{E}^{0} \mathrm{CO}_{2} / \mathrm{CO}\left(\mathrm{CH}_{3} \mathrm{CN}, \mathrm{TFE}\right)=-1.36 \mathrm{~V}$ vs $\mathrm{Fc}^{+} / \mathrm{Fc}$.

The catalytic performance of complex [1] with respect to electrochemical $\mathrm{CO}_{2}$ reduction in the presence of TFE as a proton source and different ILs or conventional benchmark [TBA] $\left[\mathrm{PF}_{6}\right]$ electrolyte, was also studied by CPE (Figure S6 and Table 3). The applied potential was -2.05 $\mathrm{V}$ vs $\mathrm{Fc}^{+} / \mathrm{Fc}$ for all CPE experiments reported, except for an additional CPE carried out in the absence of TFE at $300 \mathrm{mV}$ more positive potential $\left(-1.75 \mathrm{~V} \mathrm{vs} \mathrm{Fc}^{+} / \mathrm{Fc}\right)$. The reduction of imidazolium cations on the GC surface under those conditions was completely excluded, since very negative potentials are required for that $\left(-2.81 \mathrm{~V} \mathrm{vs} \mathrm{Fc}^{+} / \mathrm{Fc}\right.$ under $\mathrm{N}_{2}$ atmosphere and -2.65 $\mathrm{V}$ vs Fc ${ }^{+} / \mathrm{Fc}$ under $\mathrm{CO}_{2}$ atmosphere) and they were never reached on the present study. ${ }^{26}$ Carbon monoxide $(\mathrm{CO})$ and hydrogen $\left(\mathrm{H}_{2}\right)$ were the only reduction products detected, with no evidence of any additional product in solution. In all cases, $\mathrm{CO}$ remained the major reaction product and the overall faradaic yield was nearly $90 \%$ (Table 3 ). Control CPE experiments containing only [TBA] $\left[\mathrm{PF}_{6}\right]$ as supporting electrolyte were also conducted at the same potential and the ratio of gas products $\mathrm{CO} / \mathrm{H}_{2}$ in that case was found to be $98 / 2$. Comparing that with the $\mathrm{CO} / \mathrm{H}_{2}$ ratio in the presence of ILs, we observed a slight increase in $\mathrm{H}_{2}$ production for all ILs. Out of the series, [BMIM] $\left[\mathrm{PF}_{6}\right]$ and $[\mathrm{BMPyrr}]\left[\mathrm{PF}_{6}\right]$ produced the lowest rate of $\mathrm{H}_{2}$, while, on the contrary, $[\mathrm{EMIM}]\left[\mathrm{BF}_{4}\right]$ produced the highest. In all cases the current density during electrolysis was relatively stable within the range $(2-6) \mathrm{mA} / \mathrm{cm}^{2}$. In contrast, $\mathrm{CPE}$ for $\mathrm{CO}_{2}$ reduction in $0.5 \mathrm{M}$ [EMIM] $\left[\mathrm{PF}_{6}\right]$ solution without TFE reached almost total selectivity for $\mathrm{CO}$ production $(99 \%)$, but displaying a poor current density during electrolysis $\left(0.7 \mathrm{~mA} / \mathrm{cm}^{2}\right)$. Finally, CPE with [DiMIM] $\left[\mathrm{N}\left(\mathrm{SO}_{2} \mathrm{CF}_{3}\right)_{2}\right]$ as supporting electrolyte resulted in $\mathrm{H}_{2}$ production only $\left(\mathrm{FY}_{\mathrm{H} 2} 59 \%\right)$ and an important drop in current density was observed over the first $20 \mathrm{~min}$. 


\begin{tabular}{|c|c|c|c|c|}
\hline & $\begin{array}{c}\text { Electrolysis } \\
\text { potential (V) } \\
\text { vs Fc } \text { Fc }^{+} \mathbf{F c}\end{array}$ & $\begin{array}{c}\text { CPE } \\
\text { duration } \\
(\text { min })^{\mathrm{a}}\end{array}$ & $\begin{array}{c}\text { FYco } \\
(\%)^{b}\end{array}$ & $\begin{array}{l}\mathrm{FY}_{\mathrm{H} 2} \\
(\%)^{\mathrm{b}}\end{array}$ \\
\hline$[\mathrm{TBA}]\left[\mathrm{PF}_{6}\right]$ & -2.05 & 108 & $92 \pm 5$ & $2 \pm 1$ \\
\hline$\left[{\mathrm{BMIM}]\left[\mathrm{PF}_{6}\right]}\right.$ & -2.05 & 108 & $77 \pm 4$ & $8 \pm 2$ \\
\hline$[\mathrm{BMPyrr}]\left[\mathrm{PF}_{6}\right]$ & -2.05 & 62 & $80 \pm 5$ & $10 \pm 4$ \\
\hline$[\mathrm{EMIM}]\left[\mathrm{BF}_{4}\right]$ & -2.05 & 68 & $71 \pm 8$ & $18 \pm 3$ \\
\hline [EMIM][PF 6$]$ & -2.05 & 54 & $77 \pm 4$ & $12 \pm 3$ \\
\hline$[\mathrm{EMIM}]\left[\mathrm{PF}_{6}\right]^{\mathrm{c}}$ & -1.75 & $300^{\mathrm{d}}$ & $96 \pm 1$ & $1 \pm 1$ \\
\hline
\end{tabular}

Table 3. Electrolysis of $1 \mathrm{mM}$ of complex [1] in $0.5 \mathrm{M}$ supporting electrolyte in $\mathrm{CH}_{3} \mathrm{CN}$ in the presence of $1.5 \mathrm{M}$ of TFE under a $\mathrm{CO}_{2}$ saturated atmosphere. ${ }^{\mathrm{a}}$ Total electrolysis duration to circulate $14 \mathrm{C}$. ${ }^{b}$ Faradaic yield for each product $\left(\mathrm{FY}_{\mathrm{CO}}\right.$ and $\left.\mathrm{FY}_{\mathrm{H} 2}\right)$. ${ }^{\mathrm{c}}$ Electrolysis of $1 \mathrm{mM}$ of complex [1] in $0.5 \mathrm{M}$ [EMIM][PF6] in $\mathrm{CH}_{3} \mathrm{CN}$ under a $\mathrm{CO}_{2}$ saturated atmosphere. ${ }^{\mathrm{d}}$ Total electrolysis duration to circulate $10 \mathrm{C}$.

\section{DISCUSSION}

The role of ILs in $\mathrm{CO}_{2}$ electroreduction has been largely investigated in previous studies with heterogeneous catalysts where ILs have demonstrated to promote $\mathrm{CO}_{2}$ electroreduction by means of inhibiting hydrogen evolution reaction, increasing the concentration of dissolved $\mathrm{CO}_{2}$ in aqueous based solutions, thus reducing the associated mass transport limitations, as well as diminishing the energetic barrier of the reaction by formation of adducts ${ }^{23,38,39}$ with $\mathrm{CO}_{2}$, leading to $\mathrm{CO}_{2}$ activation. Studies with homogeneous catalysts for $\mathrm{CO}_{2}$ electroreduction in the presence of ILs are much fewer ${ }^{31,32}$ and the role of the structure of different ILs has never been addressed before in $\mathrm{CO}_{2}$ conversion by molecular electrocatalysis. Here, we evaluate for the first time the effect of different ILs used as supporting electrolyte in binary mixtures with acetonitrile on the electroreduction of $\mathrm{CO}_{2}$ catalyzed by a model molecular complex, namely complex [1]. In particular, within this structure-activity relationship study, we varied the nature of the cation, anion and cation alkyl chain by a choice of 5 different ILs.

Thus, we demonstrate that the presence of IL cations in solution under inert conditions (argon) greatly favors reduction of complex [1], as shown by the large impact on its redox potentials, with positive shifts of both one-electron redox events: up to $210 \mathrm{mV}$ for the first reversible reduction wave corresponding to bipyridine reduction and up to $370 \mathrm{mV}$ for the second one, which corresponds to the reduction of $\mathrm{Re}^{\mathrm{I}}$ to $\mathrm{Re}^{0}$. Furthermore, when $\mathrm{CO}_{2}$ was present without an added proton source in solution (Figure 3), almost the same potential shifts were reported for both reduction waves together with a catalytic wave developed at the second one-electron process (Table 1, catalytic conditions). This clearly demonstrates that ILs favor $\mathrm{CO}_{2}$ electroreduction as compared to [TBA] $\left[\mathrm{PF}_{6}\right]$. An in detail view of all positive shifts on the $\mathrm{CO}_{2}$ reduction potential leads to the following conclusions: (i) those shifts were very sensitive to the nature of the IL cation and all 3 imidazolium based ILs exhibited a much larger positive potential shift than pyrrolidinium based IL and benchmark electrolyte, following the trend $\mathrm{IM}^{+}$ $>\mathrm{Pyrr}^{+}>\mathrm{TBA}^{+}$; (ii) there is almost no effect on the $\mathrm{CO}_{2}$ reduction potential with respect to the size of the cation alkyl chain and the nature of the associated anion (Figure 3 ). These observations strongly indicate that the IL cation takes part in a direct interaction with the molecular catalyst. Particularly, the aforementioned potential shifts, more relevant on the 
second electron transfer, could stem from the electrostatic stabilization of the negativelycharged reduced form of complex [1] (equation 1) by the IL cations present in solution (equation 2 ). This is in agreement with the electrostatic stabilization previously suggested by Choi et al. ${ }^{32}$ for the case of iron tetraphenylporphyrin and Matsubara et al. ${ }^{31}$ for the interaction between [EMIM $^{+}$and the negatively charged reduced form of complex [1]. In addition to this, Matsubara et al. ${ }^{31}$ proposed several theoretical structures for the interaction between the imidazolium cation and the reduced form of complex [1] based on DFT calculations. One of those calculated structures suggested that the imidazolium ring lies above the bipyridine ligand due to $\pi-\pi$ interactions. It must be noted that the first one-electron reduction of complex [1] is centered on the (bpy) ligand, which is an aromatic system containing delocalized $\pi$ electrons in their $\mathrm{p}$ orbitals. Thus, our results showing overpotential diminution for $\mathrm{CO}_{2}$ reduction in the presence of ILs, which greatly depends on the nature of the IL cation (Figures 2 and 3), with the trend $\mathrm{IM}^{+}>\mathrm{Pyrr}^{+}>\mathrm{TBA}^{+}$, demonstrate the $\pi-\pi$ stacking interaction between the (bpy) $)^{-}$and the $\mathrm{IM}^{+} \mathrm{p}$ orbitals initially proposed by Matsubara et al. ${ }^{31}$ This interaction is not available neither in the case of $\mathrm{Pyrr}^{+}$nor $\mathrm{TBA}^{+}$, which explains higher stabilization effect on delocalized electrons (more relevant overpotential diminution) achieved by $\mathrm{IM}^{+}$in comparison with $\mathrm{Pyrr}^{+}$ based ILs.

$$
\begin{array}{ll}
{\left[\mathrm{Re}(\mathrm{CO})_{3}(\mathrm{bpy}) \mathrm{Cl}\right]+2 \mathrm{e}^{-}+\mathrm{CO}_{2} \Leftrightarrow\left[\operatorname{Re}(\mathrm{CO})_{3}(\mathrm{bpy}) \mathrm{CO}_{2}\right]^{-}+\mathrm{Cl}^{-}} & \text {eq. } 1 \\
{\left[\operatorname{Re}(\mathrm{CO})_{3}(\mathrm{bpy}) \mathrm{CO}_{2}\right]^{-}+\mathrm{IL}^{+} \Leftrightarrow\left[\operatorname{Re}(\mathrm{CO})_{3}(\mathrm{bpy}) \mathrm{CO}_{2}\right]^{-}\left[\mathrm{IL}^{+}\right.} & \text {eq. } 2
\end{array}
$$

In addition to the potential shift, some difference is observed in Figure $3 \mathrm{~b}$ when comparing catalytic current displayed in presence of either $[\mathrm{EMIM}]^{+}$or $[\mathrm{BMIM}]^{+}$cations. In particular, $[E M I M]\left[\mathrm{BF}_{4}\right]$ and $[\mathrm{EMIM}]\left[\mathrm{PF}_{6}\right]$ exhibited the highest $\left(\mathrm{i}_{\text {cat }} / \mathrm{i}_{\mathrm{p}}\right)$ ratio. In contrast, the other ILs reported in Table 1 gave current enhancement comparable to the benchmark electrolyte. Only the case of [EMIM] $\left[\mathrm{PF}_{6}\right]$ was studied by $\mathrm{CPE}$ at this point exhibiting low current density, but extremely high product selectivity towards $\mathrm{CO}$ generation (see Table 3 ).

Finally, electrochemical $\mathrm{CO}_{2}$ reduction in the presence of TFE as a proton source and ILs was studied by CV (Figure 4 and Table 2) and CPE experiments (Table 3 and Figure S6) leading to the following observations from CVs: (i) as expected, addition of TFE resulted in all cases in larger catalytic current densities for $\mathrm{CO}_{2}$ reduction; (ii) a small but significant and stimulating effect of ILs in decreasing overpotential was observed, reflecting the activating role of ILs also in the presence of TFE; (iii) the catalytic current ratio displayed by imidazolium and pyrrolidinium IL solutions were in all cases at least $25 \%$ higher than $\left[\mathrm{TBA}^{\mathrm{B}}\right]\left[\mathrm{PF}_{6}\right]$ containing solutions, being $[\mathrm{BMPyrr}]\left[\mathrm{PF}_{6}\right]$ the one exhibiting the highest catalytic current ratio. Furthermore, CPE experiments showed that in most cases shorter electrolysis were needed to transfer $14 \mathrm{C}$ when ILs were present in solution, since higher current densities were reached in agreement with previous CVs (Figure 4). However, the catalyst was slightly less selective in $\mathrm{CO}$ production in the presence of ILs in comparison with benchmark [TBA] $\left.\mathrm{PF}_{6}\right]$ electrolyte. [BMIM] $\left[\mathrm{PF}_{6}\right]$ and $\left.[\mathrm{BMPyrr}] \mathrm{PF}_{6}\right]$ kept a very high $\mathrm{CO} / \mathrm{H}_{2}$ ratio, 91/9 and 89/11 respectively, meanwhile [EMIM] $\left[\mathrm{BF}_{4}\right]$ led to the lowest selectivity ratio among the ILs studied (80/20). Finally, with [DiMIM] $\left[\mathrm{N}\left(\mathrm{SO}_{2} \mathrm{CF}_{3}\right)_{2}\right]$, the only protic IL tested in this work, reduction of the protons provided by the IL results in the production of $\mathrm{H}_{2}$ as the major product.

Comparing the co-catalyst effect of all ILs studied here under catalytic $\mathrm{CO}_{2}$ reduction conditions, in the presence and the absence of TFE as a proton source in solution, we demonstrated that the presence of TFE seems to weaken, at least partially, the electrostatic interaction between the reduced form of complex [1] (equation 1) and IL cations present in solution as described by equation 2 , which was responsible for the positive potential shift 
observed for both electron transfers in Figures 2 and 3. The overpotential was between 330 and $200 \mathrm{mV}$ lower than in the case of benchmark electrolyte in the absence of TFE (Table 1), but only between 70 and $30 \mathrm{mV}$ lower in the presence of TFE (Table 2). As reported by Kubiak's group, ${ }^{14} \mathrm{CO}_{2}$ reduction catalytic cycle for complex [1] follows two different pathways whether or not a proton source is present in solution. Thus, once the reduced form of the catalyst is generated by 2 electron transfers and the $\mathrm{CO}_{2}$ molecule have been incorporated in complex [1] (equation 1), two possible pathways are described. On the one hand, in the absence of a proton source, a new electron transfer takes place forming a di-anion catalytic species: $\left[\operatorname{Re}(\mathrm{CO})_{3}(\text { bpy }) \mathrm{CO}_{2}\right]^{2-}$ (equation 3 ), which can be greatly stabilized thanks to the IL cations (equation 4). On the other hand, when an explicit proton donor is added, such as TFE, a "proton first" step controls the reaction initially forming a non-charged intermediate (equation 5), which becomes a mono-anion catalytic species $\left[\operatorname{Re}(\mathrm{CO})_{3}(\mathrm{bpy}) \mathrm{CO}_{2} \mathrm{H}\right]^{-}$after the following electron transfer (equation 6). As a result, these two intermediates on the "proton first" pathway are much less stabilized by the presence of IL cations (equation 7) and for this reason the ILs exhibit a much weaker co-catalytic effect when a proton donor is present in solution.

$$
\begin{aligned}
& {\left[\operatorname{Re}(\mathrm{CO})_{3}(\mathrm{bpy}) \mathrm{CO}_{2}\right]^{-}+\mathrm{e}^{-} \Leftrightarrow\left[\operatorname{Re}(\mathrm{CO})_{3}(\mathrm{bpy}) \mathrm{CO}_{2}\right]^{2-}} \\
& {\left[\operatorname{Re}(\mathrm{CO})_{3}(\mathrm{bpy}) \mathrm{CO}_{2}\right]^{2-}+2 \mathrm{IL}^{+} \Leftrightarrow\left[\operatorname{Re}(\mathrm{CO})_{3}(\mathrm{bpy}) \mathrm{CO}_{2}\right]^{2-}[\mathrm{IL}]^{+}[\mathrm{IL}]^{+}} \\
& {\left[\operatorname{Re}(\mathrm{CO})_{3}(\mathrm{bpy}) \mathrm{CO}_{2}\right]^{-}+\mathrm{H}^{+} \Leftrightarrow\left[\operatorname{Re}(\mathrm{CO})_{3}(\mathrm{bpy}) \mathrm{CO}_{2} \mathrm{H}\right]} \\
& {\left[\operatorname{Re}(\mathrm{CO})_{3}(\mathrm{bpy}) \mathrm{CO}_{2} \mathrm{H}\right]+\mathrm{e}^{-} \Leftrightarrow\left[\operatorname{Re}(\mathrm{CO})_{3}(\mathrm{bpy}) \mathrm{CO}_{2} \mathrm{H}\right]^{-}} \\
& {\left[\operatorname{Re}(\mathrm{CO})_{3}(\mathrm{bpy}) \mathrm{CO}_{2} \mathrm{H}\right]^{-}+\mathrm{IL}^{+} \Leftrightarrow\left[\operatorname{Re}(\mathrm{CO})_{3}(\mathrm{bpy}) \mathrm{CO}_{2} \mathrm{H}\right]^{-}[\mathrm{IL}]^{+}}
\end{aligned}
$$

eq. 3

eq. 4

eq. 5

eq. 6

eq. 7

\section{CONCLUSIONS}

In conclusion, for the first time a structure-activity study by comparing the role as co-catalyst of different ILs, including pyrrolidinium and imidazolium based ILs, for $\mathrm{CO}_{2}$ electroreduction with a model molecular catalyst is presented here. We have proved by CV and CPE that the use of ILs as a supporting electrolyte in acetonitrile does not only ensure appropriate conductivity, but also displays co-catalyst features. More particularly, we have demonstrated that under both inert and $\mathrm{CO}_{2}$ atmosphere, the negatively-charged reduced forms of complex [1] (mono- and di-anion intermediates) are electrostatically stabilized by the IL cations. This stabilization gives as a result an important IL cation-dependent overpotential diminution when compared to a conventional benchmark supporting electrolyte. Moreover, we have demonstrated the $\pi-\pi$ stacking interaction between imidazolium cations and (bpy) ${ }^{-} \mathrm{p}$ orbitals, which is responsible for their outstanding performance as co-catalyst in comparison with pyrrolidinium based ILs. However, this co-catalyst effect of ILs becomes less relevant in the presence of a proton source in solution due to the formation of a non-charged intermediate as a result of protonation (equation 5). CPE experiments in the presence of TFE demonstrated a slight decrease of selectivity for CO production when ILs were in solution. Nevertheless, higher current densities during CPEs were reached in the presence of ILs as supporting electrolyte, which indicated an additional effect of ILs improving the catalytic reaction rate. To sum up, $\left[\mathrm{BMPyrr}_{[}\left[\mathrm{PF}_{6}\right]\right.$ and $[\mathrm{BMIM}]\left[\mathrm{PF}_{6}\right]$ exhibit the lowest overpotential and the highest $\mathrm{CO}$ selectivity among the ILs studied in the presence of TFE as a proton source. 


\section{SUPPORTING INFORMATION}

The Supporting Information is available free of charge on the ACS Publications website. DOI: XXXX

Additional $\mathrm{CV}$ figures, current density evolution during $\mathrm{CPE}$ and $\mathrm{H}_{2} \mathrm{O}$ content quantification in

$0.5 \mathrm{M} \mathrm{IL}$ in $\mathrm{CH}_{3} \mathrm{CN}$ solutions before and after ILs drying treatment.

\section{AUTHOR INFORMATION}

\section{Corresponding author}

*E-mail for C.M.S.-S.: carlos.sanchez@upmc.fr

*E-mail for M.F.:marc.fontecave@ college-de-france.fr

*E-mail for M.G.-M.:maria.gomez@college-de-france.fr

\section{Notes}

The authors declare no competing financial interest.

\section{ACKNOWLEDGEMENT}

This work was supported by the "Génie des Procédés"' PhD Program of Sorbonne Université. E.V. would like to thank the Onassis foundation for financial support (Grant number: F ZO 012-1/ 2018-2019).

\section{REFERENCES}

(1) Qiao, J.; Liu, Y.; Hong, F.; Zhang, J. A Review of Catalysts for the Electroreduction of Carbon Dioxide to Produce Low-Carbon Fuels. Chem. Soc. Rev. 2014, 43 (2), 631-675. https://doi.org/10.1039/C3CS60323G.

(2) Francke, R.; Schille, B.; Roemelt, M. Homogeneously Catalyzed Electroreduction of Carbon Dioxide-Methods, Mechanisms, and Catalysts. Chem. Rev. 2018, 118 (9), 4631-4701. https://doi.org/10.1021/acs.chemrev.7b00459.

(3) Benson, E. E.; Kubiak, C. P.; Sathrum, A. J.; Smieja, J. M. Electrocatalytic and Homogeneous Approaches to Conversion of $\mathrm{CO}_{2}$ to Liquid Fuels. Chem. Soc. Rev. 2009, 38 (1), 89-99. https://doi.org/10.1039/B804323J.

(4) Costentin, C.; Robert, M.; Savéant, J.-M. Catalysis of the Electrochemical Reduction of Carbon Dioxide. Chem. Soc. Rev. 2013, 42 (6), 2423-2436. https://doi.org/10.1039/C2CS35360A.

(5) Hawecker, J.; Lehn, J.-M.; Ziessel, R. Photochemical and Electrochemical Reduction of Carbon Dioxide to Carbon Monoxide Mediated by $\left(2,2^{\prime}-\right.$ Bipyridine)Tricarbonylchlororhenium(I) and Related Complexes as Homogeneous Catalysts. Helv. Chim. Acta 1986, 69 (8), 1990-2012. https://doi.org/10.1002/hlca.19860690824.

(6) Hawecker, J.; Lehn, J.-M.; Ziessel, R. Electrocatalytic Reduction of Carbon Dioxide Mediated by $\operatorname{Re}(B i p y)(\mathrm{CO}) 3 \mathrm{Cl}$ (Bipy = 2,2'-Bipyridine). J. Chem. Soc. Chem. Commun. 1984, 6, 328-330. https://doi.org/10.1039/C39840000328. 
(7) Nakazawa, M.; Mizobe, Y.; Matsumoto, Y.; Uchida, Y.; Tezuka, M.; Hidai, M. Electrochemical Reduction of Carbon Dioxide Using Iron-Sulfur Clusters as Catalyst Precursors. Bull. Chem. Soc. Jpn. 1986, 59 (3), 809-814. https://doi.org/10.1246/bcsj.59.809.

(8) Ogura, K.; Yoshida, I. Electrocatalytic Reduction of $\mathrm{CO}_{2}$ to Methanol: Part 9: Mediation with Metal Porphyrins. J. Mol. Catal. 1988, 47 (1), 51-57. https://doi.org/10.1016/03045102(88)85072-7.

(9) Smieja, J. M.; Sampson, M. D.; Grice, K. A.; Benson, E. E.; Froehlich, J. D.; Kubiak, C. P. Manganese as a Substitute for Rhenium in $\mathrm{CO}_{2}$ Reduction Catalysts: The Importance of Acids. Inorg. Chem. 2013, 52 (5), 2484-2491. https://doi.org/10.1021/ic302391u.

(10) Leung, K.; Nielsen, I. M. B.; Sai, N.; Medforth, C.; Shelnutt, J. A. Cobalt-Porphyrin Catalyzed Electrochemical Reduction of Carbon Dioxide in Water. 2. Mechanism from First Principles. J. Phys. Chem. A 2010, 114 (37), 10174-10184. https://doi.org/10.1021/jp1012335.

(11) Beley, Marc.; Collin, J. Paul.; Ruppert, Romain.; Sauvage, J. Pierre. Electrocatalytic Reduction of Carbon Dioxide by Nickel Cyclam $^{2+}$ in Water: Study of the Factors Affecting the Efficiency and the Selectivity of the Process. J. Am. Chem. Soc. 1986, 108 (24), 7461-7467. https://doi.org/10.1021/ja00284a003.

(12) Costentin, C.; Drouet, S.; Robert, M.; Savéant, J.-M. A Local Proton Source Enhances $\mathrm{CO}_{2}$ Electroreduction to $\mathrm{CO}$ by a Molecular Fe Catalyst. Science 2012, 338 (6103), 90 94. https://doi.org/10.1126/science.1224581.

(13) Hawecker, J.; Lehn, J.-M.; Ziessel, R. Efficient Photochemical Reduction of $\mathrm{CO}_{2}$ to $\mathrm{CO}$ by Visible Light Irradiation of Systems Containing $\operatorname{Re}(\mathrm{Bipy})(\mathrm{CO})_{3} \mathrm{X}$ or $\mathrm{Ru}(\mathrm{Bipy})_{3}{ }^{2+}{ }_{-}$ $\mathrm{Co}^{2+}$ Combinations as Homogeneous Catalysts. J. Chem. Soc. Chem. Commun. 1983, 9, 536-538. https://doi.org/10.1039/C39830000536.

(14) Clark, M. L.; Cheung, P. L.; Lessio, M.; Carter, E. A.; Kubiak, C. P. Kinetic and Mechanistic Effects of Bipyridine (Bpy) Substituent, Labile Ligand, and Brønsted Acid on Electrocatalytic $\mathrm{CO}_{2}$ Reduction by $\mathrm{Re}$ (Bpy) Complexes. ACS Catal. 2018, 8 (3), 2021-2029. https://doi.org/10.1021/acscatal.7b03971.

(15) Manbeck, G. F.; Muckerman, J. T.; Szalda, D. J.; Himeda, Y.; Fujita, E. Push or Pull? Proton Responsive Ligand Effects in Rhenium Tricarbonyl $\mathrm{CO}_{2}$ Reduction Catalysts. $J$. Phys. Chem. B 2015, 119 (24), 7457-7466. https://doi.org/10.1021/jp511131x.

(16) Sung, S.; Kumar, D.; Gil-Sepulcre, M.; Nippe, M. Electrocatalytic $\mathrm{CO}_{2}$ Reduction by Imidazolium-Functionalized Molecular Catalysts. J. Am. Chem. Soc. 2017, 139 (40), 13993-13996. https://doi.org/10.1021/jacs.7b07709.

(17) Blakemore, J. D.; Gupta, A.; Warren, J. J.; Brunschwig, B. S.; Gray, H. B. Noncovalent Immobilization of Electrocatalysts on Carbon Electrodes for Fuel Production. J. Am. Chem. Soc. 2013, 135 (49), 18288-18291. https://doi.org/10.1021/ja4099609.

(18) Alvarez-Guerra, M.; Albo, J.; Alvarez-Guerra, E.; Irabien, A. Ionic Liquids in the Electrochemical Valorisation of $\mathrm{CO}_{2}$. Energy Environ. Sci. 2015, 8 (9), 2574-2599. https://doi.org/10.1039/C5EE01486G.

(19) Hapiot, P.; Lagrost, C. Electrochemical Reactivity in Room-Temperature Ionic Liquids. Chem. Rev. 2008, 108 (7), 2238-2264. https://doi.org/10.1021/cr0680686.

(20) Hanc-Scherer, F. A.; Sánchez-Sánchez, C. M.; Ilea, P.; Herrero, E. Surface-Sensitive Electrooxidation of Carbon Monoxide in Room Temperature Ionic Liquids. ACS Catal. 2013, 3 (12), 2935-2938. https://doi.org/10.1021/cs4007364.

(21) Montiel, M. A.; Solla-Gullón, J.; Sanchez-Sanchez, C. M. Electrochemical Reactivity and Stability of Platinum Nanoparticles in Imidazolium-Based Ionic Liquids. J. Solid State Electrochem. 2016, 20 (4), 1043-1052. https://doi.org/10.1007/s10008-015-30145 . 
(22) Grills, D. C.; Matsubara, Y.; Kuwahara, Y.; Golisz, S. R.; Kurtz, D. A.; Mello, B. A. Electrocatalytic $\mathrm{CO}_{2}$ Reduction with a Homogeneous Catalyst in Ionic Liquid: High Catalytic Activity at Low Overpotential. J. Phys. Chem. Lett. 2014, 5 (11), 2033-2038. https://doi.org/10.1021/jz500759x.

(23) Sanchez-Sanchez, C. M. Electrocatalytic Reduction of $\mathrm{CO}_{2}$ in Imidazolium-Based Ionic Liquids. In Reference Module in Chemistry, Molecular Sciences and Chemical Engineering. Encyclopedia of Interfacial Chemistry: Surface Science and Electrochemistry; Wandelt, K., Ed.; Elsevier, Oxford, U.K., 2018; Vol. 5, pp 539-551.

(24) Rosen, B. A.; Salehi-Khojin, A.; Thorson, M. R.; Zhu, W.; Whipple, D. T.; Kenis, P. J. A.; Masel, R. I. Ionic Liquid-Mediated Selective Conversion of $\mathrm{CO}_{2}$ to $\mathrm{CO}$ at Low Overpotentials. Science 2011, 334 (6056), 643-644. https://doi.org/10.1126/science.1209786.

(25) Hanc-Scherer, F. A.; Montiel, M. A.; Montiel, V.; Herrero, E.; Sánchez-Sánchez, C. M. Surface Structured Platinum Electrodes for the Electrochemical Reduction of Carbon Dioxide in Imidazolium Based Ionic Liquids. Phys. Chem. Chem. Phys. 2015, 17 (37), 23909-23916. https://doi.org/10.1039/C5CP02361K.

(26) Zhao, S.-F.; Horne, M.; Bond, A. M.; Zhang, J. Is the Imidazolium Cation a Unique Promoter for Electrocatalytic Reduction of Carbon Dioxide? J. Phys. Chem. C 2016, 120 (42), 23989-24001. https://doi.org/10.1021/acs.jpcc.6b08182.

(27) Wang, Y.; Hayashi, T.; He, D.; Li, Y.; Jin, F.; Nakamura, R. A Reduced Imidazolium Cation Layer Serves as the Active Site for Electrochemical Carbon Dioxide Reduction. $\begin{array}{llllll}\text { Appl. } & \text { Catal. } & B & \text { Environ. } & \text { 2020, } & 264,\end{array}$ https://doi.org/10.1016/j.apcatb.2019.118495.

(28) Lau, G. P. S.; Schreier, M.; Vasilyev, D.; Scopelliti, R.; Grätzel, M.; Dyson, P. J. New Insights Into the Role of Imidazolium-Based Promoters for the Electroreduction of $\mathrm{CO}_{2}$ on a Silver Electrode. J. Am. Chem. Soc. 2016, 138 (25), 7820-7823. https://doi.org/10.1021/jacs.6b03366.

(29) Papasizza, M.; Cuesta, A. In Situ Monitoring Using ATR-SEIRAS of the Electrocatalytic Reduction of $\mathrm{CO}_{2}$ on $\mathrm{Au}$ in an Ionic Liquid/Water Mixture. ACS Catal. 2018, 8 (7), 6345-6352. https://doi.org/10.1021/acscatal.8b00977.

(30) Medina-Ramos, J.; DiMeglio, J. L.; Rosenthal, J. Efficient Reduction of $\mathrm{CO}_{2}$ to $\mathrm{CO}$ with High Current Density Using in Situ or Ex Situ Prepared Bi-Based Materials. J. Am. Chem. Soc. 2014, 136 (23), 8361-8367. https://doi.org/10.1021/ja501923g.

(31) Matsubara, Y.; Grills, D. C.; Kuwahara, Y. Thermodynamic Aspects of Electrocatalytic $\mathrm{CO}_{2}$ Reduction in Acetonitrile and with an Ionic Liquid as Solvent or Electrolyte. ACS Catal. 2015, 5 (11), 6440-6452. https://doi.org/10.1021/acscatal.5b00656.

(32) Choi, J.; Benedetti, T. M.; Jalili, R.; Walker, A.; Wallace, G. G.; Officer, D. L. High Performance Fe Porphyrin/Ionic Liquid Co-Catalyst for Electrochemical $\mathrm{CO}_{2}$ Reduction. Chem. - Eur. J. 2016, 22 (40), 14158-14161. https://doi.org/10.1002/chem.201603359.

(33) Montiel, M. A.; Solla-Gullón, J.; Montiel, V.; Sánchez-Sánchez, C. M. Electrocatalytic Studies on Imidazolium Based Ionic Liquids: Defining Experimental Conditions. Phys. Chem. Chem. Phys. 2018, 20 (28), 19160-19167. https://doi.org/10.1039/C8CP02662A.

(34) Azcarate, I.; Costentin, C.; Robert, M.; Savéant, J.-M. Through-Space Charge Interaction Substituent Effects in Molecular Catalysis Leading to the Design of the Most Efficient Catalyst of $\mathrm{CO}_{2}$-to-CO Electrochemical Conversion. J. Am. Chem. Soc. 2016, 138 (51), 16639-16644. https://doi.org/10.1021/jacs.6b07014.

(35) Kemna, A.; García Rey, N.; Braunschweig, B. Mechanistic Insights on $\mathrm{CO}_{2}$ Reduction Reactions at Platinum/[BMIM] $\left[\mathrm{BF}_{4}\right]$ Interfaces from In Operando Spectroscopy. ACS Catal. 2019, 9 (7), 6284-6292. https://doi.org/10.1021/acscatal.9b01033. 
(36) Ratschmeier, B.; Kemna, A.; Braunschweig, B. Role of $\mathrm{H}_{2} \mathrm{O}$ for $\mathrm{CO}_{2}$ Reduction Reactions at Platinum/Electrolyte Interfaces in Imidazolium Room-Temperature Ionic Liquids. ChemElectroChem 2020, 7 (7), 1765-1774. https://doi.org/10.1002/celc.202000316.

(37) Sullivan, B. P.; Bolinger, C. M.; Conrad, D.; Vining, W. J.; Meyer, T. J. One- and TwoElectron Pathways in the Electrocatalytic Reduction of $\mathrm{CO}_{2}$ by $\mathrm{Fac}-\mathrm{Re}(\mathrm{Bpy})(\mathrm{CO}) 3 \mathrm{Cl}$ (Bpy $=$ 2,2'-Bipyridine). J. Chem. Soc. Chem. Commun. 1985, 20, 1414-1416. https://doi.org/10.1039/C39850001414.

(38) Wang, Y.; Hatakeyama, M.; Ogata, K.; Wakabayashi, M.; Jin, F.; Nakamura, S. Activation of $\mathrm{CO}_{2}$ by Ionic Liquid EMIM-BF 4 in the Electrochemical System: A Theoretical Study. Phys. Chem. Chem. Phys. 2015, 17 (36), 23521-23531. https://doi.org/10.1039/C5CP02008E.

(39) Papasizza, M.; Yang, X.; Cheng, J.; Cuesta, A. Electrocatalytic Reduction of $\mathrm{CO}_{2}$ in Neat and Water-Containing Imidazolium-Based Ionic Liquids. Curr. Opin. Electrochem. 2020, 23, 80-88. https://doi.org/10.1016/j.coelec.2020.04.004. 
TOC Graphic

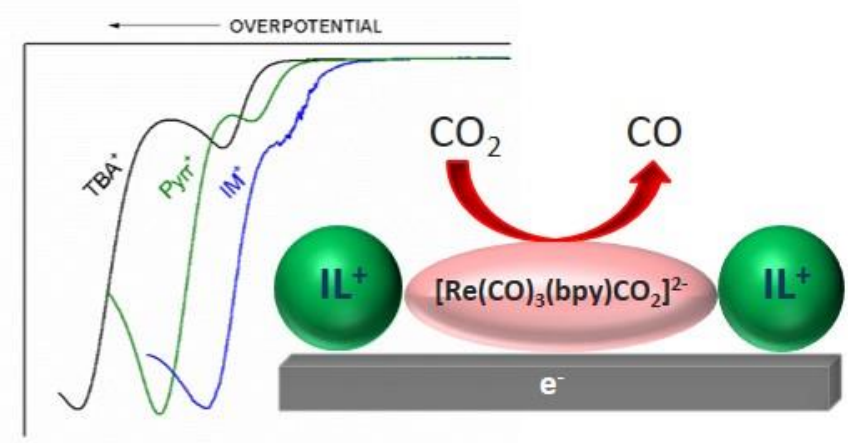

